\title{
ENCEFALITIS AUTOINMUNE MEDIADA POR ANTICUERPOS CONTRA EL RECEPTOR N-METIL-D-ASPARTATO: REPORTE DE CUATRO CASOS EN PERÚ
}

\author{
Henry Palomino-Lescano1,a , Darwin Segura-Chávez, ${ }^{1, a}$, Darko Quispe-Orozco ${ }^{1, a}$, Sheila Castro-Suarez ${ }^{2, a}$, \\ Walter De la Cruz ${ }^{3, a, b}$, Willy Zapata-Luyo ${ }^{3, a}$, José Delgado-Ríos ${ }^{3, a, c}$, Juan Cam,a,d, Marcela Alvarado-Morales ${ }^{1, a}$, \\ Lippmann Paredes-Carcasi ${ }^{1, a}$, Iván Cornejo-Herrera ${ }^{5, a}$, María Meza-Vega ${ }^{2, a, e}$
}

\begin{abstract}
RESUMEN
La encefalitis autoinmune por anticuerpos contra el receptor N-metil-D-aspartato (anti-NMDAR) es un desorden mediado por anticuerpos contra antígenos de superficie neuronal, cuyo diagnóstico temprano y tratamiento oportuno mejoran el pronóstico de la enfermedad. Se presentan cuatro casos con el diagnóstico definitivo de encefalitis autoinmune por anti-NMDAR, tratados en el Instituto Nacional de Ciencias Neurológicas en Lima-Perú. Todos los pacientes presentaron crisis epilépticas y tres casos desarrollaron un estado epiléptico refractario. Asimismo, tres pacientes presentaron alteraciones neuropsiquiátricas, discinesias y disautonomías. Dos casos requirieron soporte ventilatorio. Todos presentaron un electroencefalograma anormal, dos casos tuvieron pleocitosis en líquido cefalorraquídeo, y sólo uno mostró anormalidades cerebrales en la resonancia magnética. Respecto al tratamiento, todos los pacientes recibieron inmunoterapia con metilprednisolona y sólo dos de ellos requirieron plasmaféresis por respuesta ineficaz al tratamiento con corticoides. A los 12 meses del alta hospitalaria, tres pacientes quedaron libre de crisis epilépticas y sólo un caso no logró la independencia funcional. Estos casos muestran que la encefalitis anti-NMDAR es una condición tratable y su reconocimiento temprano junto con un tratamiento adecuado (inmunoterapia/plasmaféresis) son esenciales para una evolución favorable.
\end{abstract}

Palabras clave: Informes de Casos; Encefalitis Antirreceptor N-Metil-D-Aspartato; Perú (fuente: DeCS BIREME).

\section{AUTOIMMUNE ENCEPHALITIS MEDIATED BY ANTIBODIES AGAINST THE N-METHYL-D-ASPARTATE RECEPTOR: REPORT OF FOUR CASES IN PERU}

\begin{abstract}
Autoimmune encephalitis with antibodies against the $\mathrm{N}$-methyl-D-aspartate receptor (anti-NMDAR) is a disorder mediated by antibodies against neural surface antigens, whose early diagnosis and timely treatment improve the prognosis of the disease. Four cases with the definitive diagnosis of autoimmune encephalitis by anti-NMDAR are presented, treated at the National Institute of Neurological Sciences in Lima-Peru. All patients had epileptic seizures and three cases developed a refractory epileptic state. In addition, three patients presented neuropsychiatric alterations, dyskinesias, and dysautonomia. Two cases required ventilatory support. All presented an abnormal electroencephalogram; two cases had pleocytosis in cerebrospinal fluid, and only one showed brain abnormalities on MRI. Regarding treatment, all patients received methylprednisolone immunotherapy and only two of them required plasma exchange for an ineffective response to corticosteroid treatment. After 12 months of hospital discharge, three patients were free of epileptic seizures and only one case did not achieve functional independence. These cases show that anti-NMDAR encephalitis is a treatable condition and its early recognition together with appropriate treatment (immunotherapy/plasmapheresis) are essential for a favorable evolution.
\end{abstract}

Keywords: Case reports; N-Methyl-D-aspartate antirreceptor encephalitis; Peru (source: MeSH NLM).

\footnotetext{
Instituto Nacional de Ciencias Neurológicas. Lima, Perú.

Centro de Investigación Básica en Demencias y Enfermedades Desmielinizantes del Sistema Nervioso, Instituto Nacional de Ciencias Neurológicas. Lima, Perú.

Departamento de investigación, docencia y atención especializada en epilepsia, Instituto Nacional de Ciencias Neurológicas. Lima, Perú.

Unidad de Cuidados Intensivos, Instituto Nacional de Ciencias Neurológicas. Lima, Perú.

Hospital Hipólito Unanue de Tacna. Tacna, Perú.

Médico neurólogo; ${ }^{\mathrm{b}}$ magíster en Farmacología; ${ }^{\mathrm{c}}$ doctor en Neurociencias; ${ }^{\mathrm{d}}$ especialista en Medicina Intensiva; ${ }^{\mathrm{e}}$ magíster en Neuropsicología.

Recibido: 16/09/2018 Aprobado: 12/12/2018 En línea: 20/03/2019
}

Citar como: Palomino-Lescano H, Segura-Chávez D, Quispe-Orozco D, Castro-Suarez S, De la Cruz W, Zapata-Luyo W, Delgado-Ríos J, Cam J, AlvaradoMorales M, Paredes-Carcasi L, Cornejo-Herrera I, Meza-Vega M. Encefalitis autoinmune mediada por anticuerpos contra el receptor N-metil-D-aspartato: reporte de cuatro casos en Perú. Rev Peru Med Exp Salud Pública. 2019;36(1):138-44. doi:10.17843/rpmesp.2019.361.3936. 


\section{INTRODUCCIÓN}

La encefalitis mediada por anticuerpos contra el receptor $\mathrm{N}$-metil D-Aspartato (anti-NMDAR) es la encefalitis autoinmune más frecuente que, se caracteriza porla presencia de síntomas psicóticos prominentes, crisis epilépticas, movimientos anormales y disfunción autonómica, los cuales pueden estar acompañados de alteraciones en el líquido cefalorraquídeo (LCR) y en el electroencefalograma (EEG) ${ }^{(1)}$. La combinación de estas características permite clasificar su diagnóstico en probable y definitivo, siendo indispensable la identificación de anticuerpos lgG contra la subunidad NR1 del receptor $\mathrm{N}$-metil D-Aspartato para alcanzar esta última categoría diagnóstica ${ }^{(1)}$.

La encefalitis anti-NMDAR afecta predominantemente a mujeres jóvenes, cuya edad promedio es de 22 años ${ }^{(1)}$. Su frecuencia en centros especializados sobrepasa la de cualquier etiología viral, y está asociada a neoplasia oculta en un 38 a $50 \%$ de los casos ${ }^{(2-4)}$, siendo el teratoma de ovario el más frecuente en mujeres adultas $(50-58 \%$ ) y el carcinoma de células germinales en varones $(5 \%)$ (4). En los casos no neoplásicos, se asume que una infección viral podría generar la producción de anticuerpos dirigidos contra antígenos de superficie neuronal ${ }^{(1)}$.

Las manifestaciones clínicas, se caracterizan por presentar una fase prodrómica con cefalea, fiebre, síntomas gastrointestinales y/o de vía respiratoria superior. Posteriormente el cuadro progresa con cambios conductuales, que pueden ser leves al inicio, hasta presentar manifestaciones psiquiátricas como delusiones, alucinaciones, insomnio y agitación psicomotriz, trastornos cognitivos como alteraciones del lenguaje y memoria ${ }^{(4)}$. Las crisis epilépticas suelen suceder a las alteraciones psiquiátricas, pueden ser focales, generalizadas o mixtas, y es frecuente el estado epiléptico muchas veces refractario a tratamiento antiepiléptico ${ }^{(3,5)}$. Los cuadros catatónicos así como los movimientos involuntarios hiperquinéticos constituyen otras de las manifestaciones habituales ${ }^{(4-6)}$. Adicionalmente, signos de disfunción autonómica como hipertermia, taquicardia, hipertensión, incontinencia urinaria, hipoventilación central y arritmias cardiacas complican aún más el estado clínico de estos pacientes, de forma que muchos requieren intubación y atención en Unidades de Cuidados Intensivos ( $\mathrm{UCl})^{(3,5)}$. Estas manifestaciones dependen de la disfunción neuronal causada por los anticuerpos, los cuales generan una internalización progresiva de los receptores NMDA, lo que a su vez trae consigo la disminución in crescendo de las corrientes sinápticas. Esto explicaría la remisión del cuadro clínico si los anticuerpos son removidos eficazmente con la aplicación de corticoides, inmunoglobulinas o de plasmaféresis ${ }^{(3,6,7)}$.

A continuación se presenta una serie de cuatro casos de pacientes adultos con diagnóstico definitivo de encefalitis
anti-NMDAR, atendidos en el Instituto Nacional de Ciencias Neurológicas (INCN) en Lima-Perú, entre el 2015 y 2017.

\section{REPORTE DE CASOS}

El diagnóstico de los cuatro casos se basó en la detección de anticuerpos IgG contra la subunidad GluN1 del receptor NMDA positivos en estudio serológico y/o LCR, mediante cultivo de células transfectadas ${ }^{(7)}$, procesados en el Instituto de Investigaciones Biomédicas «August $\mathrm{Pi}$ i Sunyer» de Barcelona-España. Cada paciente y/o sus familiares firmaron un consentimiento informado para la utilización de la información clínica respectiva. La Tabla 1 muestra las principales características clínicas de los casos reportados.

CASO 1. Varón de 17 años de edad, sin antecedentes de importancia, admitido por presentar múltiples crisis epilépticas tónico-clónico generalizadas (CETCG) de cuatro días de evolución y fiebre al ingreso. La primera muestra de LCR presentó 32 células $/ \mathrm{mm}^{3}, 100 \%$ mononucleares; el EEG mostró actividad delta polimorfa generalizada y continua con mayor amplitud en región temporal izquierda (Figura 1) y la imagen por resonancia magnética (RM) cerebral fue normal.

Ante la posibilidad de estar frente a un caso con encefalitis viral se inició tratamiento con aciclovir y fármacos antiepilépticos (FAEs), sin mejoría del cuadro clínico. Luego presentó discinesias orofaciales, movimientos coreoatetósicos de extremidades, compromiso del nivel de conciencia y mutismo, desarrolló un estado epiléptico convulsivo refractario, debido al cual ingresó a la $\mathrm{UCl}$ (Tabla 1). A los 45 días de evolución, ante la sospecha de encefalitis autoinmune, se inició tratamiento inmunosupresor con $1 \mathrm{~g} /$ día de metilprenisolona por vía endovenosa (EV) por cinco días seguido de $60 \mathrm{mg} / \mathrm{día}$ de prednisona, tras lo cual la evolución fue favorable. Un segundo EEG fue anormal, caracterizado por el patrón «extreme delta brush» (Figura 1). La ecografía testicular fue normal. La Tabla 2 muestra los principales hallazgos de los casos reportados.

CASO 2. Mujer de 20 años de edad, sin antecedentes, presentó inicialmente cefalea, dolor abdominal, náuseas y vómitos. Cuatro días después presentó CETCG, posteriormente irritabilidad, verborrea, agitación psicomotriz y heteroagresividad, fue ingresada a un hospital psiquiátrico, sin mejoría. A los 20 días de enfermedad fue admitida en nuestra institución, se evidenció, desorientación, lenguaje ininteligible y fiebre persistente. El estudio del LCR y RM cerebral no presentó alteraciones.

Se instauró tratamiento con aciclovir, sin mejoría. Fue ingresada a $\mathrm{UCl}$ por un estado epiléptico refractario, que requirió inducción al coma barbitúrico. Luego se agregaron automatismos oromandibulares, posturas distónicas intermitentes en miembros superiores, rigidez, 
Tabla 1. Características clínicas de los pacientes con encefalitis autoinmune mediada por anticuerpos contra el receptor N-metil-D-Aspartato en el Instituto Nacional de Ciencias Neurológicas, Lima-Perú.

\begin{tabular}{|c|c|c|c|c|}
\hline Característica clínica & Caso 1 & Caso 2 & Caso 3 & Caso 4 \\
\hline Edad (años) & 17 & 20 & 19 & 60 \\
\hline Sexo & Masculino & Femenino & Masculino & Femenino \\
\hline \multicolumn{5}{|l|}{ Síntoma prodrómico } \\
\hline Cefalea & No & Sí & Sí & No \\
\hline Vómito & No & Sí & No & No \\
\hline Alza térmica & No & No & Sí & No \\
\hline \multicolumn{5}{|l|}{ Síntoma inicial } \\
\hline Agitación psicomotriz & No & No & Sí & No \\
\hline Pensamiento desorganizado & No & No & No & Sí \\
\hline Crisis epiléptica TCG & Sí & Sí & No & No \\
\hline \multicolumn{5}{|l|}{ Manifestación psiquiátrica } \\
\hline Agitación psicomotriz & No & Sí & Sí & No \\
\hline Heteroagresividad & No & Sí & Sí & No \\
\hline Verborrea & No & Sí & No & No \\
\hline Mutismo & No & No & Sí & No \\
\hline Alucinaciones & No & No & No & Sí \\
\hline \multicolumn{5}{|l|}{ Manifestación extrapiramidal } \\
\hline Discinesia orofacial & Sí & Sí & Sí & No \\
\hline Discinesia apendicular & Sí & Sí & Sí & No \\
\hline Distonía & No & Sí & No & No \\
\hline \multicolumn{5}{|l|}{ Manifestación autonómica } \\
\hline Taquicardia & Sí & Sí & Sí & No \\
\hline Hipotensión & Sí & No & Sí & No \\
\hline \multicolumn{5}{|l|}{ Estado epiléptico } \\
\hline Refractario & Sí & Sí & Sí & No \\
\hline
\end{tabular}

TCG: tónico clónica generalizada.

disautonomía y fiebre. El EEG mostró una actividad delta polimorfa generalizada continua con mayor amplitud en región temporal izquierda y que en el hemisferio cerebral derecho muestra además actividad rápida superpuesta (Figura 2). Se le administró dos ciclos de metilprednisolona EV (1g/día por cinco días cada ciclo) con discreta mejoría.

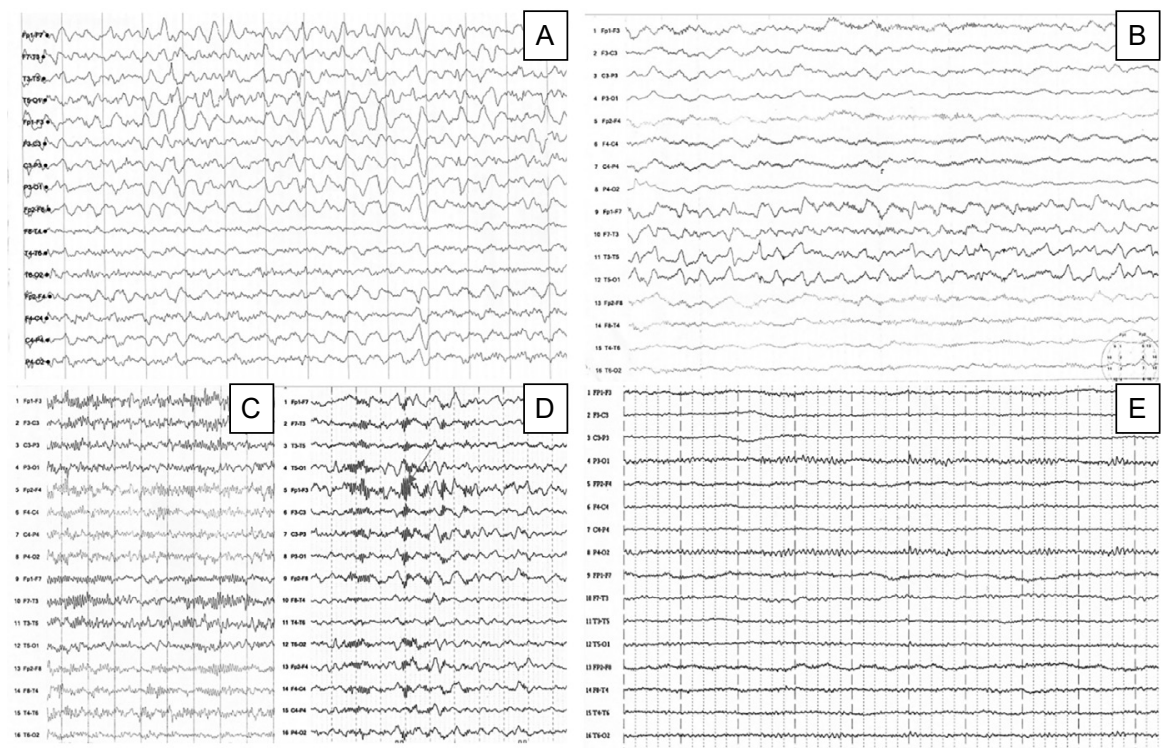

Figura 1. Registros de EEG del caso 1 en diferentes periodos de tiempo. A-D: hay presencia de actividad delta polimórfica, generalizada y continua, con mayor amplitud en región temporal izquierda que en C. D: muestra actividad rápida superpuesta (patrón «delta brush») que señala la flecha. E: muestra EEG normal nueve meses después del alta. 
Tabla 2. Hallazgos en líquido cefalorraquídeo, neuroimágenes, electroencefalograma, tratamiento y resultados del tratamiento de los pacientes con encefalitis autoinmune mediada por anticuerpos contra el receptor N-metil D-Aspartato en el Instituto Nacional de Ciencias Neurológicas, Lima-Perú.

\begin{tabular}{|c|c|c|c|c|}
\hline Características & Caso 1 & Caso 2 & Caso 3 & Caso 4 \\
\hline \multicolumn{5}{|l|}{ Líquido cefalorraquídeo } \\
\hline Leucocitos (células $/ \mathrm{mm}^{3}$ ) & 32 & 18 & 5 & 2 \\
\hline Porcentaje de MMN & 100 & 90 & 100 & 100 \\
\hline Proteínas (mg/dL) & 17 & 25 & 43 & 20 \\
\hline Glucosa (mg/dL) & 46 & 55 & 86 & 34 \\
\hline Hallazgos en RM cerebral & Normal & Normal & Normal & Anormal \\
\hline \multicolumn{5}{|l|}{ Hallazgos en EEG } \\
\hline Patrón «delta brush» & Sí & No & No & Sí \\
\hline Enlentecimiento focal y/o generalizado & Sí & Sí & Sí & Sí \\
\hline Descarga epileptiforme focal o generalizada & No & No & Sí & No \\
\hline Presencia de tumor subyacente & No & No & No & No \\
\hline Uso de corticoides & Sí & Sí & Sí & Sí \\
\hline Uso de plasmaféresis & No & Sí & Sí & No \\
\hline Uso de ventilación mecánica & No & Sí & Sí & No \\
\hline Escala de Rankin modificado al inicio & $\mathrm{V}$ & V & V & III \\
\hline Escala de Rankin modificado a los 12 meses & I & III & II & I \\
\hline Ausencia de crisis a los 12 meses & Sí & Sí & Sí & No \\
\hline Recurrencia de encefalitis a los 12 meses de seguimiento & No & Sí & Sí & Sí \\
\hline
\end{tabular}

LCR: líquido cefalorraquídeo; MMN: mononucleares; EEG: electroencefalograma; RM: resonancia magnética.

Posteriormente se le realizó plasmaféresis, tras ello hubo importante mejoría clínica. En la tomografía y ecografía pélvica no se evidenció teratoma.

CASO 3. Varón de 19 años de edad, previamente sano, presentó cefalea pulsátil, alza térmica, luego desorientación, habla incoherente, irritabilidad, agitación psicomotriz y heteroagresividad de curso fluctuante. Cuatro días después presentó CETCG. Se inició tratamiento con aciclovir sin mejoría. Durante su estancia hospitalaria cursó con disminución del nivel del estado de conciencia, fiebre, dificultad respiratoria y estado epiléptico superrefractario.

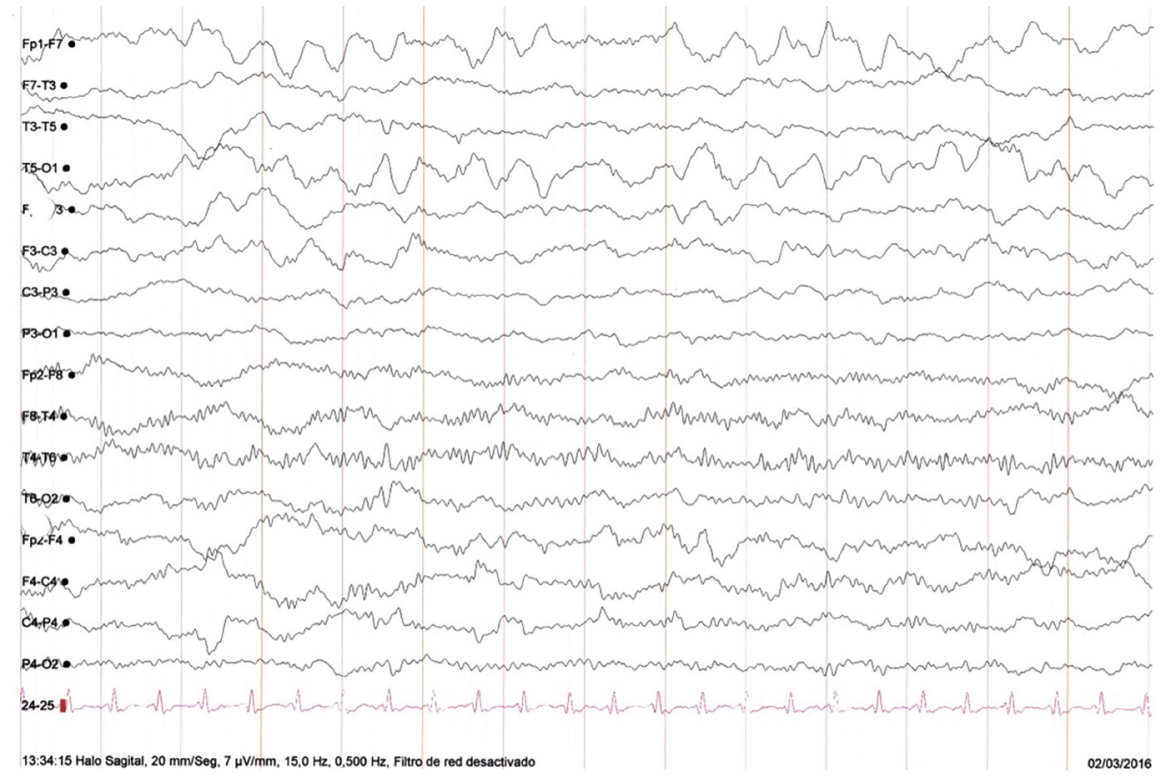

Figura 2. Registro de EEG del caso 2 que muestra actividad delta polimórfica generalizada continua con mayor amplitud en región temporal izquierda que en el hemisferio cerebral derecho muestra además actividad rápida superpuesta. 
Se le indujo al coma barbitúrico, sin mejoría sostenida; se asociaron discinesias orolinguofaciales, distonía en miembros superiores y disautonomía. El EEG mostró descargas repetitivas punta-onda lenta, de distribución bifrontal además de actividad delta rítmica intermitente frontal (FIRDA). El estudio de LCR mostró 5 células $/ \mathrm{mm}^{3}$ con $100 \%$ mononucleares. La RM cerebral fue normal.

Se administró metilprednisolona EV (1g/día por cinco días), seguido de hidrocortisona y prednisona con escasa mejoría, se decidió dar un segundo pulso de metilprednisolona sin resultados. El paciente permaneció cinco meses en $\mathrm{UCI}$, cuatro en ventilación mecánica, finalmente fue sometido a plasmaféresis, tras lo cual cursó con notable mejoría clínica progresiva. No se encontró neoplasia asociada en el estudio tomográfico.

CASO 4. Mujer de 60 años, sin antecedentes, inició sintomatología con alteración conductual, tendencia a la tristeza, comportamiento desorganizado, desorientación y pérdida del reconocimiento de rostros familiares; luego presentó crisis epilépticas tónicas de miembro superior derecho con generalización secundaria, controladas parcialmente conlaadministración deFAEs. Trasunestudio de LCR y tomografía normal, fue transferida a psiquiatría. Donde además de las alteraciones conductuales y crisis tónicas presentó crisis gelásticas e insomnio. En días posteriores, las crisis aumentaron en frecuencia, sin recuperación de conciencia entre las mismas, por lo que fue admitida a nuestra institución. Durante la hospitalización presentó alucinaciones visuales como «visión de animales». El estudio de LCR fue normal y la RM cerebral mostró lesiones cortico-subcorticales en ambos lóbulos frontales y temporal derecho hipointensos en T1, hiperintensas en FLAIR/T2, sin captación de sustancia de contraste ni restricción de la difusión, además de lesiones inespecíficas de sustancia blanca (Figura 3). EEG en vigilia con enlentecimiento de la actividad de fondo y actividad delta theta intermitente generalizada.

Se administró metilprednisolona EV (1 g/d por cinco días), con importante mejoría clínica progresiva. Un año después paciente presenta recurrencia del cuadro que remitió tras la corticoterapia.
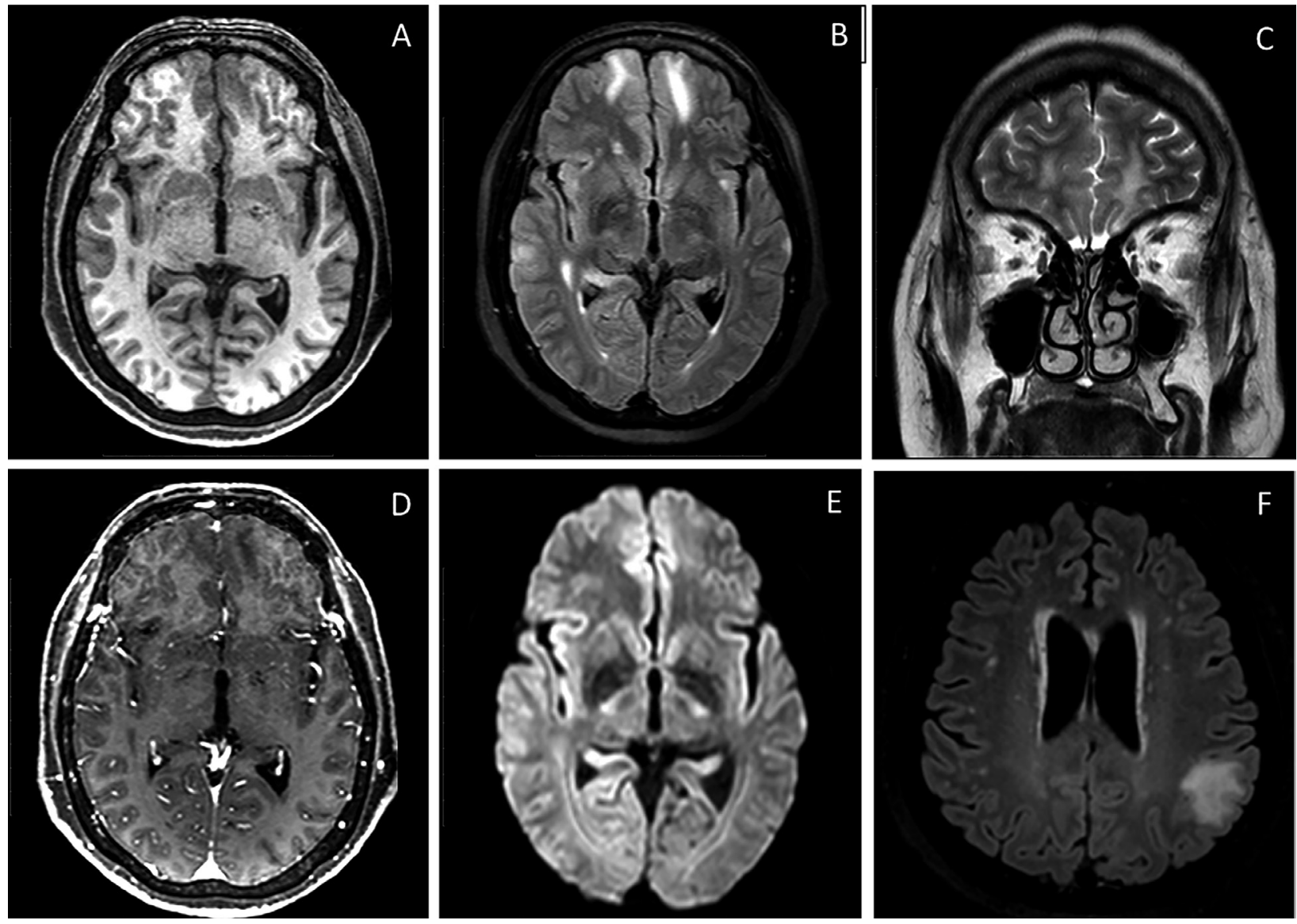

Figura 3. Imágenes de resonancia magnética del caso 4. A: lesiones cortico-subcorticales en ambos lóbulos frontales y temporal derecho hipointensas en T1. B y C: imágenes hiperintensas en FLAIR/T2. D: imágenes no muestran captación de sustancia de contraste. E: imágenes sin restricción de la difusión ni captación de sustancia de contraste. F: Un año después durante recurrencia de la encefalitis se evidencia lesión que compromete sustancia blanca subcortical parietal izquierda, hiperintensa en FLAIR y lesiones inespecíficas de sustancia blanca. 


\section{DISCUSIÓN}

Se presentan cuatro casos de pacientes con diagnóstico de encefalitis autoinmune anti receptor NMDA definitiva, todos los pacientes presentaron positividad para el anticuerpo lgG contra la subunidad NR1 del receptor NMDA en suero y LCR ${ }^{(7)}$; la mediana de edad fue 20 años (rango: 17 a 60) y dos fueron mujeres. A pesar de la búsqueda con ecografías y tomografías, ningún caso tuvo asociación neoplásica; a diferencia de otras series donde la frecuencia de neoplasia es de $50 \%$, una posible explicación de esto es que esta serie está conformada por dos varones y una mujer con edad superior a los 45 años en donde la frecuencia de tumores asociados es menor ${ }^{(1,4)}$. Ninguno de los tres casos reportados previamente en nuestro medio tuvo asociación neoplásica ${ }^{(8,9)}$. Sin embargo es necesario continuar la vigilancia puesto que estos cuadros pueden preceder a la neoplasia por algunos años ${ }^{(1,4)}$.

Las crisis epilépticas fueron la manifestación neurológica inicial en dos casos, los otros dos iniciaron con alteraciones conductuales. Sin embargo, de acuerdo a lo reportado por Titulaer et al. (1), la mayoría inicia con alteración conductual y menos de $20 \%$ con crisis epilépticas. En los reportes nacionales, se publicó previamente el caso de una paciente de 23 años que inició con crisis epilépticas farmacorresistentes con posterior compromiso neuropsiquiátrico ${ }^{(8)}$; el de una niña de cuatro años que inició con automatismos y posteriormente desarrolló irritabilidad y agitación psicomotriz y el de un paciente de 31 años que debutó con síndrome apático, abúlico y luego manifestó desinhibición y agresividad ${ }^{(9)}$. A lo largo de la enfermedad en la serie reportada, todos los casos desarrollaron crisis epilépticas, en su mayoría CETCG, tres pacientes desarrollaron un estado epiléptico refractario y uno de ellos un estado epiléptico superrefractario, mientras tanto tres casos, tuvieron alteración conductual, y el compromiso de memoria y lenguaje fue prominente en dos casos. Series más extensas señalan que aproximadamente $70 \%$ de pacientes adultos desarrolla crisis epilépticas a lo largo de la enfermedad, y más del $90 \%$ desarrolla alteración cognitiva y conductual $(1,4,10)$.

La encefalitis autoinmune constituye la primera causa de estado epiléptico refractario de etiología no identificada en las primeras 48 horas ${ }^{(11)}$. Por ende, es importante sospecharla en casos de estado epiléptico refractario de novo en aras de un tratamiento oportuno, asimismo, el compromiso psiquiátrico, orienta al diagnóstico de encefalitis anti-NMDAR.

Se ha descrito que las manifestaciones neuropsiquiátricas y las crisis epilépticas, constituyen sintomatología de origen cortical y ocurren al inicio de la enfermedad, mientras que las de origen subcortical, como los trastornos del movimiento, disautonomía y reducción del nivel conciencia, ocurren entre 10 a 20 días más tarde ${ }^{(10,12)}$. De forma similar en esta serie, los tres casos que manifestaron movimientos involuntarios, los presentaron en estadios tardíos de la enfermedad y todos ellos cursaron con disautonomía, hipoventilación y necesitaron de soporte intensivo. Se reporta una gran variabilidad en la presentación de los movimientos involuntarios, tales como, corea, atetosis, distonías, y discinesias orofaciales con movimientos estereotipados de los brazos ${ }^{(13,14)}$

Estas manifestaciones dependen de la disfunción neuronal causada por los anticuerpos, los cuales generan una recaptación selectiva e internalización de los receptores NMDA, lo que a su vez trae consigo la disregulación glutamatérgica y dopaminérgica, que puede ser revertida una vez que los anticuerpos son removidos, sin afectar la supervivencia celular ${ }^{(3)}$. Las diferencias en la región donde el NMDAR está predominantemente agotado (general, corticolímbico, o hipocampo-parahipocampal) influyen en el fenotipo resultante. Estos cambios fisiopatológicos explicarían plausiblemente el detrimento progresivo de las funciones superiores, la psicosis similar a la esquizofrenia y disquinesias características de este tipo de encefalitis; así como la pobre respuesta al uso de fármacos antiepilépticos (FAEs) en el control de las crisis epilépticas. Sin embargo el cuadro clínico podría remitir si los anticuerpos son diezmados eficazmente con el uso de corticoides, inmunoglobulinas o el uso de plasmaféresis ${ }^{(3)}$.

Si bien todos los casos tuvieron EEG anormal, sólo un caso, presentó el típico delta brush, esto concuerda con el $30 \%$ señalado por la literatura ${ }^{(13)}$. Respecto al estudio de LCR, este mostró pleocitosis linfocítica en tres casos, esta característica es frecuente al inicio de la enfermedad y por lo general desaparece con la progresión de la encefalitis ${ }^{(12)}$. La RM fue normal en tres casos, similar a lo reportado en otras series donde la RM no muestra anormalidad en el $60 \%$ de los casos, en el restante $40 \%$ se han descrito áreas de hiperseñal en hipocampo, región frontobasal, insular, cerebelo, núcleos basales y lesiones inespecíficas de sustancia blanca ${ }^{(1,4,14)}$.

El manejo de la encefalitis por anticuerpos anti-NMDAR está centrado en la inmunoterapia y la búsqueda tumoral. En general, las no asociadas a tumor van a responder mejor a la inmunoterapia. Las terapias de primera línea incluyen esteroides, inmunoglobulina endovenosa o plasmaféresis; mientras que en las terapias de segunda línea están rituximab y ciclofosfamida ${ }^{(15)}$. Los buenos resultados clínicos, tal como se definen por las reducciones en las puntuaciones de la escala de Rankin modificado, se correlacionaron con la disminución de los niveles de anticuerpos anti-NMDAR y se asociaron con una inmunoterapia temprana ${ }^{(5)}$. En los casos reportados, todos fueron tratados inicialmente con pulsos de corticoides; hubo adecuada respuesta terapéutica en dos casos, los otros dos casos requirieron plasmaféresis, tras lo cual hubo mejoría. El intervalo para la administración de este tratamiento fue prolongado debido a la falta de accesibilidad, sin embargo, llama la atención la evolución clínica notablemente favorable del caso 3 , tras la plasmaféresis, luego de estar cinco meses en cuidados intensivos. 
El propósito de este reporte es resaltar que la encefalitis antiNMDAR es una condición tratable que afecta a personas jóvenes y cuya omisión en el diagnóstico diferencial puede condicionarmuerte o discapacidad evitable.Ante la presencia de un cuadro de crisis epilépticas farmacorresistentes de novo, estado epiléptico refractario, sobre todo si está asociado a síntomas psiquiátricos y compromiso cognitivo de instauración subaguda, se debe pensar en la encefalitis autoinmune anti-NMDAR. Finalmente, es importante incidir en la dificultad para realizar el diagnóstico en los hospitales del Ministerio de Salud debido a que el panel de anticuerpos de superficie neuronal no se encuentra disponible; por lo que contar con las pruebas diagnósticas apropiadas es una necesidad fundamental para mejorar el rendimiento diagnóstico y terapéutico en estos pacientes.

Agradecimientos: A Josep Dalmau del IDIBAPS por el apoyo brindado para realizar el panel de anticuerpos contra antígenos de superficie neuronal. A Víctor Osorio Marcatinco por su colaboración en la recolección de datos. A Estuardo Melón
Rodríguez, Victor Arias Hancco y Javier Aguilar Casasola, por su colaboración para el estudio de anticuerpos.

Contribuciones de los autores: HPL y DQO han participado en la concepción y diseño del artículo, recolección de resultados, análisis e interpretación de datos, redacción del artículo, revisión crítica del artículo, y aprobación de la versión final. ShCS, WDIC y WZL han participado en la revisión crítica del artículo, redacción del artículo, aprobación de la versión final, análisis e interpretación de datos. MMV, JDR, y JC han participado en la revisión crítica del artículo, aprobación de la versión final, y aporte de pacientes o material de estudio. MAM, LPC y ICH, han participado en la recolección de resultados, redacción del artículo, revisión crítica del artículo, y aprobación de la versión final. DSCh ha participado en la concepción y diseño del artículo, análisis e interpretación de datos, revisión crítica del artículo, y aprobación de la versión final.

Fuentes de financiamiento: autofinanciado.

Conflictos de interés: los autores declaran no tener conflictos de interés.

\section{REFERENCIAS BIBLIOGRÁFICAS}

1. Titulaer MJ, McCracken L, Gabilondo I, Armangué T, Glaser C, Iizuka T, et al. Treatment and prognostic factors for long-term outcome in patients with anti-NMDA receptor encephalitis: an observational cohort study. Lancet Neurol. 2013;12(2):157-65.

2. Gable MS, Sheriff H, Dalmau J, Tilley $\mathrm{DH}$, Glaser CA. The frequency of autoimmune N-methyl-D-aspartate receptor encephalitis surpasses that of individual viral etiologies in young individuals enrolled in the California Encephalitis Project. Clin Infect Dis Off Publ Infect Dis Soc Am. 2012;54(7):899-904.

3. Dalmau J. NMDA receptor encephalitis and other antibody-mediated disorders of the synapse: The 2016 Cotzias Lecture. Neurology. 2016;87(23):2471-82.

4. Dalmau J, Gleichman AJ, Hughes EG, Rossi JE, Peng X, Lai M, et al. Anti-NMDA-receptor encephalitis: case series and analysis of the effects of antibodies. Lancet Neurol. 2008;7(12):1091-8.

5. Irani SR, Bera K, Waters P, Zuliani L, Maxwell S, Zandi MS, et al. N-methyl-D-aspartate antibody encephalitis: temporal progression of clinical and paraclinical observations in a predominantly non-paraneoplastic disorder of both sexes. Brain J Neurol. 2010;133(Pt 6):1655-67.

6. Dalmau J, Geis C, Graus F. Autoantibodies to Synaptic Receptors and Neuronal Cell Surface Proteins in Autoimmune Diseases of the Central Nervous System. Physiol Rev. 2017;97(2):839-87.

7. Graus F, Titulaer MJ, Balu R, Benseler $S$, Bien CG, Cellucci T, et al. A clinical approach to diagnosis of autoimmune encephalitis. Lancet Neurol. 2016;15(4):391-404

8 Palomino-Lescanol HY, De la Cruz W, Segura-Chávez D, Delgado-Ríos JC. Encefalitis por anticuerpos contra receptores de N-metil-D-aspartato y síndrome de DRESS secundario a fenitoína: Reporte de un caso. Rev Neuropsiquiatr. 2017;80(3):200-205. doi: 10.20453/rnp. v80i3.3157.

9 Custodio N, Escobar-MontalvoJ.Síntomas neuropsiquiátricos en encefalitis por anticuerpos contra el receptor N-metil-D-aspartato: a propósito de dos casos. An. Fac. med. 2016;77(3):277-81.

10 Gastaldi M, Thouin A, Vincent A. Antibody-Mediated Autoimmune Encephalopathies and Immunotherapies. Neurotherapeutics. 2016;13(1):147-162.
11. Niehusmann P, Dalmau J, Rudlowski C, Vincent A, Elger CE, Rossi JE, et al. Diagnostic value of $\mathrm{N}$-methyl-D-aspartate receptor antibodies in women with new-onset epilepsy. Arch Neurol. 2009;66(4):458-64.

12. Toledano M, Pittock SJ. Autoimmune Epilepsy. Semin Neurol. 2015;35(3):245-58.

13. Gaspard N, Foreman BP, Alvarez V, Cabrera Kang C, Probasco JC, Jongeling AC, et al. New-onset refractory status epilepticus: Etiology, clinical features, and outcome. Neurology. 2015;85(18):1604-13.

14. Irani SR, Vincent A. NMDA receptor antibody encephalitis. Curr Neurol Neurosci Rep. 2011;11(3):298-304.

15. Dalmau J, Lancaster E, Martinez-Hernandez E, Rosenfeld MR, Balice-Gordon R. Clinical experience and laboratory investigations in patients with anti-NMDAR encephalitis. Lancet Neurol. 2011;10(1):63-74.

Correspondencia: Henry Palomino Lescano.

Dirección: Jr. Juan Antonio Ribeyro 149, 802

Torre $C$.

Teléfono: 989570802

Correo electrónico:henrypalomino27@gmail.com 